employment of local heat followed by the use of the static wave current.

\section{Massage and Exercises.}

Massage is very useful in the later stages, but it should only be employed when it causes no pain. The manipulations should be very gentle at first, so as to promote removal of exudation and to relieve the tension. Afterwards more vigorous massage is most efficacious in dispersing the indurations and fibrous thickenings, and in removing the stiffness of the affected parts. General massage should not be employed, but the tender and affected areas should be carefully marked out for treat ment. Massage should not be used to affected joints, but only around them, so as to improve the circulation in their neighbourhood. I have frequently seen the most disastrous results to joints from their over-zealous manipulation by masseurs and masseuses, as such treatment only in creases the inflammation and bruises the synovial fringes. The same remarks apply with equal force to acute affections of the bursae and tendon sheaths, and to fibrositis of nerve sheaths until the acute affection has entirely subsided.

During the very painful stage of muscular rheumatism as complete rest as possible of the affected muscles must be enforced, but later on exercises of the muscles are of great benefit. Either light dumb-bells or Indian clubs, of from $1 \mathrm{lb}$. to $2 \mathrm{lb}$. in weight, should be employed, and such movements are to be performed as will bring the affected muscles into action. The exercises should be performed on rising in the morning, and should not occupy more than from ten to fifteen minutes. After the exercises a cold or tepid bath should be taken, and the skin be briskly rubbed with a rough towel.

In cases of chronic subcutaneous fibrosis in very fat people (adiposis dolorosa) massage is quite ineffective, and often unbearably painful. In such cases it is essential, first of all, to get rid of the superabundant fat by means of a strict diet, and by the administration of thyroid gland.

Surgical Treatment.

In a few cases, generally of long standing, where the fibrous nodules do not yield to the measures above mentioned, and where by implication of, or pressure upon, nerves they cause persistent pain, excision may be necessary.

Adhesions in the subacromial bursa have sometimes been treated by breaking them down under an anaes. thetic, but the procedure is a dangerous one, as the normal joint structures are more easily torn than the dense adhesions in the bursa, and the brachial plexus and axillary vein are liable to be damaged. Another objection is that when the adhesions alone are ruptured there is a tendency for them to re-form.

\section{Spa Treatment.}

This is most useful in protracted cases of fibrositis, especially when the waters are strongly radio-active. Undoubtedly the radio-active emanations of such waters are powerful adjuncts in the dispersion of the thickenings and deposits.

Diet.

Unlike gout, no special dieting is required in these affections. Moderation should be the keynote of all prone to the various forms of fibrositis, and especially should they avoid foods which their experience has taught them to be apt to produce gastro-intestinal fermentation. It has become of late years a fashionable craze to attribute many of these forms of "chronic rheumatism" to uric acid, but I am firmly convinced that that harmless byproduct of the human economy plays no part whatever in the development of the various forms of chronic rheumatism or fibrositis.

\section{Underclothing.}

With regard to the underclothing that should be worn by rheumatic individuals, I must confess that I am a convert to the view that porous linen underwear is the most suitable. It allows of the free evaporation of perspiration, and so prevents a more or less sodden garment from remaining in contact with the skin, which so frequently happens with those who wear woollen underclothing. I am convinced that in the latter case euch sodden garments are a frequent cause of many of the forms of fibrositis. Some individuals find that in winter linen underwear is too cold, and in such cseses o thin silk vest may be worn over the linen. This will be found to constitute a thoroughly warm, comfortable, and safe form of underwear.

\section{Residence.}

The most suitable soil is gravel, sandstone, or rock, at a fair elevation, and with good subsoil drainage. Houses should be built on a bed of concrete, so as to prevent entirely the entrance of ground air. Residence on a clay soil should be avoided if possible, but in my experience the worst soil of all is a shallow gravel soil in a cup or depression of clay, which allows the subsoil water to accumulate and frequently to reach close to the surface. Many of the gravel sites lauded by house agents are veritable traps for the development of fibrositis.

1 Ware. Amer. Journ. Med. Sci., July, 1901.2 Schmidt, Med. Klinik, 1910, vi, pp. 731-735. 8 K Küter, Archiv f. klin. Chir., vol. Ixvii, p. 1013,

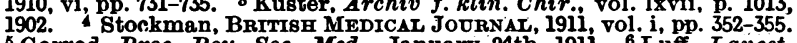
${ }_{6}^{5}$ Garrod, Proc. Roy. Soc. Med., January 24th, 1911. 6. Luf. Lancet.

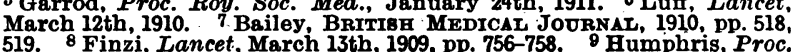
Roy. Soc. Med., March, 1910.

\section{A STUDY OF THE TYPES OF ORGANISM IN A SERIES OF BONE AND JOINT TUBERCULOSIS OF CHILDREN.}

By JOHN FRASER, M.D., Ch.M., F.R.C.S.E.,

ASSISTANT SURGEON, SICK CHILDREN'S HOSPITAL, EDINBURGH (From the Royal College of Physicians' Laboratory, Edinburgh.)

The British Royal Commission justified its existence when it showed, beyond all manner of doubt, that human tuberculosis was in a certain proportion of cases due to infection with the bovine bacillus. It has remained for individual observers to investigate local groups of tuberculosis, and to expose the relative types of bacilli present. I wish to record some investigations of a study of 70 cases of bone and joint tubercle.

\section{Technique.}

The preliminary necessity was to obtain in pure culture the actual organism which produced the lesion of an individual case; as it is exceedingly difficult, and in the majority of cases impossible, to cultivate the tubercle bacillus directly from an active lesion, guinea-pigs were used as intermediaries. The diseased tissue, obtained in each case by operation, was inoculated into the animal subcutaneously or in bulk. For a period of six weeks the ainmal was permitted to live; at the end of that time the disease was extensive in the glands and the internal organs, and from them the organism was easily cultivated.

There are various suitable media, and of such Dorset's ${ }^{3}$ egg medium is undoubtedly the best; it is a preparation of egg-yolk and water, sloped, and inspissated in tubes. Upon the surface of the medium portions of the diseased organs are rubbed, and it is of advantage sometimes to actually wound the surface of the medium. The inoculated tubes, sealed with paraffin to prevent evaporation and infection, are incubated. In fourteen days a growth is apparent.

With the growth of the organism the first step is completed. The second stage consists in identifying the organism, and this identification is at once proceeded with. There can be no doubt that it is possible to distinguish absolutely between the human and bovine types of the bacilli. Cultural and morphological tests are uncertain in their interpretation.

A bacillus which grows rapidly and profusely upon egg medium is in all probability human, yet there exists a margin of doubt, which deprives the test of any absolute value, and the same applies to morphological distinctions. A short, squat bacillus staining uniformly suggests a bovine origin, but occasionally human bacilli possess identical characters.

1. There are three tests which give trustworthy evidence of the type of bacilli. In 1905 Theobald Smith ${ }^{9}$ formulated a test, which depended upon the changes produced in glycerine bouillon by the growth of the tubercle bacillus. The glycerine bouillon is rendered faintly acid, and the 
acidity is carefully estimated by titration; 0.05 per cent. is a suitable degree. The tubercle grows as a pellicle upon the surface of the medium, and at intervals of ten days small quantities of the fluid are removed and the acidity estimated. In the case of the human bacillus the degree of acidity progressively increases; in the instance of the bovine bacillus the acidity diminishes and the medium may even become alkaline. T'he test is reliable, but it is difficult to perform, and mixed infection of the medium is very hard to prevent; should such occur the experiment is useless.

2. The second reliable test is based upon the fact that glycerine exerts a stimuiating effect upon the growth of the human bacillus, while it has a distinctly retardative influence on the bovine bacillus (Cobbet). ${ }^{2}$ The glycerine is incorporated with Dorset's egg medium (4 per cent.), and upon this medium the organism under investigation is grown. Control inoculations are made with fully identified human and bovine bacilli. By the rate and degree of growth of the bacillus its identity is established. The bovine organism grows scantily, if at all; the human bacillus spreads rapidly and profusely.

3. The simplest and yet the most reliable test is that usually termed the animal test. It is based upon the fact that the bovine bacillus is especially virulent for certain animals, more especially the calf and the rabbit. If a rabbit of an average weight of 2,000 grams is inoculated intravenously with a small amount $(0.01 \mathrm{mg}$.) of the suspected organism, one of two results will follow. If the bacillus is human the animal will show little change, its weight will remain constant or increase, and if at the end of six months it is killed and examined the tuberculous disease will be found to be limited to a few chronic lesions in the internal organs. The result of inoculation of a bovine bacillus is very different. After inoculation the animal rapidly emaciates and loses weight; in six weeks it is usually dead, and a post. mortem examination shows an acute miliary tuberculosis. The test is absolutely reliable, and the smaller the quantity of bacilli introduced the greater the difference (Oehlecker). ${ }^{6}$

\section{Investigation of Cases.}

In each individual case a systematic plan was followed * The diseased tissue was inoculated into a guinea-pig, and from the infected animal the organism was grown in the manner I have, described. The identity of the organism was established by submitting it to a series of five tests, and observations were made upon (1) the cultural characters, (2) the morphological appearances, (3) the distinctive growth upon glycerine egg medium, (4) the reaction upon glycerine bouillon, (5) the result of rabbit inoculation. From the result of these tests a definite result was come to.as regards the identity of the bacillus: Tests 1,2, 3 and 5 were carried out in every case; Test 4 was performed only in eleven instances.

\section{Results.}

On every occasion the diseased material was obtained by operation. The proportion of bone and joint cases in the series was practically equal-39 were instances of joint disease, 31 of bone disease. The age incidence was absolutely limited to 12 years and under. The cases were patients of the Edirburgh Sick Children's Hospital, and therefore may be said to have been drawn from a comparatively localized area." For two reasons the series may be considered unique - the age limit and the localized sources from which the material was obtained.

Small groups of bone and joint tubercle have been investigated by different observers.

The British Koyal Commission ${ }^{8}$ examined 14 cases, with one exception adults; 13 of the series were due to the human bacillus; 1 case was found to contain both human and the bovine bacilli. Park and Krumweide? investigated a series of 17 cases; 6 of these were children under 5 years of age, 10 were children from 5 to 16 years old, and there was a single adult case. In every instance a human bacillus was the causative factor.

Kossel, Weber, and Heuss ${ }^{5}$ published the results of an examination of 36 cases; 12 were obtained from adults and each contained the human bacillus; 24 were cases of

* For full details of experiments see the Journal of Experimental Mfedicine, vol. xvi, No, 4, 1912, p. 432. children, ages ranging from 1 to 16 years, and one of these contained the bovine bacillus. Henschen, Jundell and Svensson ${ }^{4}$ investigated a small series of 3 cases; they were adults, and all owed their origin to the human bacillus. Burckhardt ${ }^{1}$ has recently investigated a series of cases of surgical tuberculosis; the group included 29 cases of bone and joint tabercle. He found that 3 cases of joint tuberculosis contained the bovine bacillus. The respective ages were 11,19 , and 14 years.

I have to announce results which are very different from any of the above. Out of a total of 70 investigations, in 41 instances the bovine bacillus was present, in 26 cases the human bacillus occurred, and from the remaining 3 cases both human and bovine types were isolated.

These results are so striking that one naturally seeks for factors which may help to explain their uniqueness, and the factors which have most bearing are those of age, family history, and milk supply.

Age.

The age incidence has been absolutely limited to 12 years and under. This limitation is all-important, for in such an age group there are certain special distinctions.

1. The feeding is of a special type-milk, human or cow's, is the staple article of diet.

2. The lymphatic and absorptive arrangements of the abdomen are peculiar-a fact which is evidence of the high percentage of occurrences of abdominal tuberculosis ( 4 per cent., Thomson ${ }^{10}$ ).

Bearing these facts in mind, there is much to be learnt from a study of the age tables of the series. The facts are best illustrated by dividing the age period into groups : Group 1, to 3 years; Group 2, from 3 to 6 years ; Group 3, from 6 to 12 years.

In the first group the questions of milk feeding and unusual lymphatic arrangements have their strongest bearings. Twenty-eight cases were included in the first series; twenty-three of them were bovine and five were human. In the second and third series the proportions were more equal. In group No. 2 ten were due to the human bacillus, nine to the bovine bacillus. In group No. 3 eleven were human, while nine were bovine.

TABLE I.-Type of Bacillus in 67 Children in Relation to Age.

\begin{tabular}{|c|c|c|c|}
\hline Age Period. & & Human Organism. & Bovine Organism. \\
\hline To 3 years ... ... & $\ldots$ & 5 & 23 \\
\hline From 3 to 6 years & $\ldots$ & 10 & 9 \\
\hline From 6. to 12 years & $\ldots$ & 11 & 9 \\
\hline
\end{tabular}

Family History.

As a matter of routine, the family history was noted in each case investigated. In 21 instances there was a definite history of pulmonary tuberculosis having occurred in some member of the family in which the child lived, and in 50 per cent. of these cases the child was actually living in contact with a consumptive.

The practical bearing is more evident when it is stated that out of the 21 above mentioned cases 15, or 71 per cent., were due to the bacillus of human taberculosis.

- In 52 cases there was definitely stated to be no family history of tubercle; 43 of these were bovine in origin, while only 9 , or 17 per cent., were human. The difference is very striking, and the figures of the first group are explained by direct infection of the child from the consumptive patient with whom it stayed.

TABLE II.-Types of Bacillus in Relation to Family History.

\begin{tabular}{l|c|c|c}
\hline & $\begin{array}{c}\text { Human } \\
\text { Bacillus. }\end{array}$ & $\begin{array}{c}\text { Bovine } \\
\text { Bacillus. }\end{array}$ & $\begin{array}{c}\text { Percentage } \\
\text { of Human. }\end{array}$ \\
\hline $\begin{array}{c}\text { History of pulmonary tubercle } \\
\text { in family }\end{array}$ & 15 & 6 & 71 \\
No history of tubercle in family & 9 & 43 & 17 \\
\hline
\end{tabular}

Milk Supply.

Practically speaking, the bovine bacillus is introduced into the body by a single route-that of infection from the 
alimentary tract, and the medium by which it is introduced is infected milk. As far as possible observations were noted of the source of milk supply in each of the above cases; 25 cases were nourished in infancy upon human milk, 41 were entirely fed upon cow's milk; in 3 instances the source of origin was doubtful.

Of the 25 cases brought up on human milk, in only 6 cases was the bovine bacillus found. The remaining 19 were infected with the human type. In the second group, those nourished upon cow's milk, out of a total of 41, no less than 37 were due to infection with the bovine bacillus. The remaining 4 were human. In the complete series there were 4 children less than 1 year old. All these children were nourished upon cow's milk, and in every case the bovine bacillus was the organism present.

TABLE III.-Types of Organism in Relation to Milk.

\begin{tabular}{|c|c|c|c|}
\hline \multicolumn{2}{|c|}{ Source of Milk. } & Human Bacillus. & Bovine Bacillus. \\
\hline Human milk & $\ldots \quad \ldots$ & 19 & 6 \\
\hline Cow's milk... & $\ldots$ & 4 & 37 \\
\hline
\end{tabular}

It is interesting to note that in no instance was any attempt.made to sterilize or pasteurize the milk.

\section{Conclusions.}

1. It is possible by certain tests to distinguish between human and bovine types of tubercle bacilli.

2. A considerable proportion of bone and joint tubercle of children in Edinburgh is due to infection by the bovine bacillus.

3. The bovine bacillus is introduced into the body by the drinking of infected milk.

4. A considerable proportion of the cases of tubercle due to the human bacillus are the result of the direct infection of the child by a consumptive co-resident.

My thanks are due to Mr. Stiles and Dr. James Ritchie for materials and help. The McCunn and the Carnegie Trustees have provided financial assistance, and I wish to acknowledge my indebtedness to them.

REFERENCEs.
1 Burckhardt, H.: Deut. Zeit. für Chimurg., Bd. cvi, 1910, s. 1. 2 Cobbet, L.: Royal Commission Reports, Second Interim Report, 1911, Part I, 13

4 Dorset, M.: American Medicine, 1902, iii, p. 555.

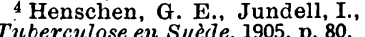

Tuberculose en Suedde, 1905, p. 80. Tuss: Tuberk, arb. a.d.k. Gesundheitsamte, 1904, i, S. 1 ; 1905 , iii, S. 1 .

6 Oehlecker, F.: Tuberk. arb. a.d.k. Gesundheitsante, 1907, vi, S. 88. 7 Park, W. H., and Krumweide, C.: Stuclies from the Public Health Laboratories of New York, 1910

8 Royal Commission Report, Final Report, 1911, Part I, p. 13

10 Thomson, J.: British Journal of Tuberculosis, 1907, i, p. 250.

THE International Congress on the prevention of the THE International Congress on the prevention will be deterioration \&ind the adulteration of foodstuffs whent on August 1st, 2nd, and 3rd. M. Henry Carton de Wiart, Minister of Justice, is an honorary president, and the presidents are the Burgomasters of Brussels, Ghent, Antwerp, and Liége. The work of the congress will be divided into four sections: Chemistry hygiene ; consumption, education and popularization; legislation. Among the subjects on the programme of discussions are the following: Protection of food substances against dirt; Regulation of the production and of the trade in table waters (mineral, aërated, etc.) as well as of ice and 'water sold to consumers; Is it necessary to institute offlcial methods for the analysis of foods? Regulation of the production and trade of milk and its by-products destined for human food; To what degree can the incorporation of antiseptics be tolerated in foodstuffs? The basis of organization of a service of inspection in the trade and in the manufacture of foodstuffs; The conditions of places of production (factories) of foodstuffs and retail shops. Rules for the washing of glasses in public-houses. Reports to be presented should be in the hands of the secretary before May lst, 1913. In connexion with the congress there will be an exposition of foodstuffs and the methods by which they are prepared for consumption, and by which they are adulterated. Thie milk supply will occupy a prominent place in the exhibition, well-kept and badly-kept farms, and the right and wrong method of transport, and so forth, being shown. Communications should be addressed to M. Antony Neuckens, Secretary of the Congress and the Exhibition, Hôtel de Ville, Brussels.

\section{CLINICAL DEMONSTRATION OF AN OPERATION FOR PROLAPSUS UTERI COM- PLICATED BY HYPERTROPHY OF THE CERVIX.:}

By W. E. FOTHERGILL, M.A., B.Sc., M.D., SURGEON TO THE ST. MARY'S HOSPITALS, AND ASSISTANT GYNAECOLOGICAL SURGEON TO THE MANCHESTER ROYAL INFIRMARY.

WHeN prolapse is complicated by hypertrophy of the cervix, it is usual to begin the operation for its relief by amputating a suitable portion of the cervix, and suturing the resulting wound in the customary way. Then an anterior colporrhaphy is performed, a fresh incision being made separate from that required for the amputation of the cervix. If the anterior vaginal wall is removed at all freely the two incisions approach one another very closely, a poor and narrow bridge of sound tissue being left between them. Further, the amputation of the cervix tends to shorten the anterior vaginal wall; and thus, when the colporrhaphy has been completed, the cervix still points downwards and forwards, and the uterus is left in a

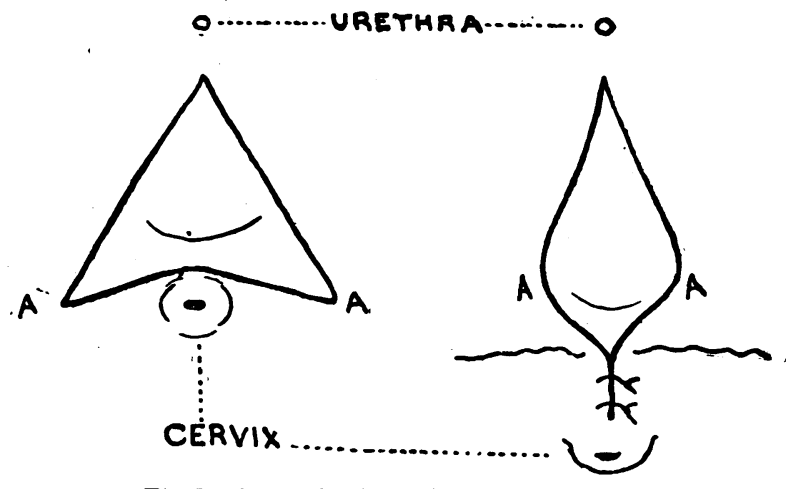

Fig. 1.-Colporrhaphy incision for prolapse.
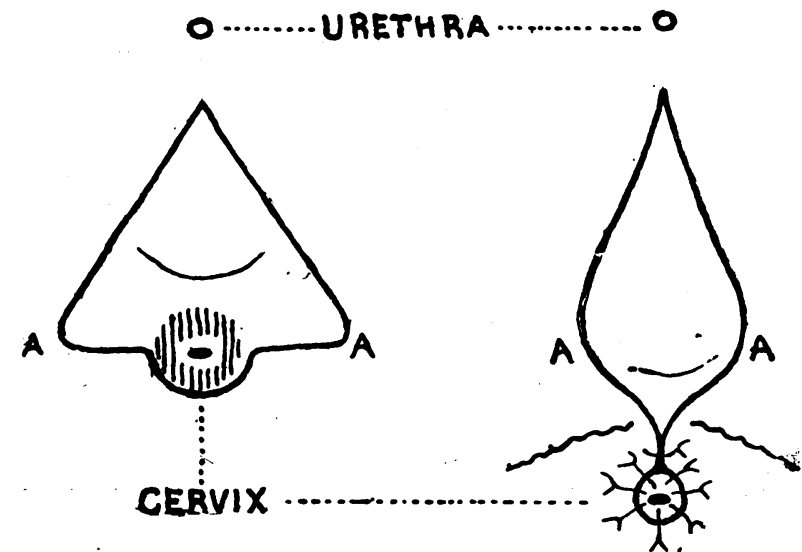
Fig. 2.-Incision for amputation of cervix with colpor
prolapse complicated by hypertrophy of cervix.

position of retroversion which is very favourable to the recurrence of prolapse.

For some time $I$ have been using a single incision for both the amputation of the cervix and the anterior colporrhaphy, and have found the results more satisfactory than those obtained by doing the operations separately one after the other.

In order to make clear this little modification in technique it is necessary to explain once more how I treat ordinary cases of prolapse in which the cervix is not hypertrophied. The anterior colporrhaphy is done so that the wound is broad above and narrows to a point near the urethral orifice. The piece of vaginal wall removed is, ronghly, an equilateral triangle with its base touching the cervix and its apex near the opening of the urethra. The easiest way of making the incision is to pull down the cervix with a vulsellum and then to pick up with forceps two points about 3 in. apart, one directly to the right, the other directly to the left of the

* Given in the Post-Graduate Course at the Manchester Royal 